\title{
Back to work: evaluation of a multidisciplinary rehabilitation program with emphasis on mental symptoms; A two-year follow up
}

This article was published in the following Dove Press journal:

Journal of Multidisciplinary Healthcare

22 June 2012

Number of times this article has been viewed

\author{
Rita Sjöström ${ }^{1,2}$ \\ Ragnar Asplund ${ }^{3}$ \\ Marie Alricsson ${ }^{2,4}$ \\ 'Strömsund Health Centre, Jämtland \\ County Council, Strömsund, \\ ${ }^{2}$ Department of Health Sciences, Mid \\ Sweden University, Östersund, \\ ${ }^{3}$ The Research and Development Unit, \\ Jämtland County Council, Östersund, \\ ${ }^{4}$ School of Human Sciences, \\ Linnaeus University, Kalmar, Sweden
}

Background: The aim of this investigation was to analyze temporal changes in anxiety, depression, and stress in patients with musculoskeletal pain for a period of up to 2 years after a multidisciplinary rehabilitation program, in relation to sick-listing (registered with The Swedish Social Insurance Agency [Forsakringskassan] for sickness benefit).

Methods: Ten persons with full-time sick leave (absence from work for medical reasons) (group 1) and 49 with part-time or no sick leave (group 2) at the end of the 2-year study period participated. It was shown in a previous study that group 1 had higher pain rating and higher subjective physical disability than group 2, with little or no improvement during and after rehabilitation. In the present study, all participants were evaluated with the Hospital Anxiety and Depression scale and a self-rated stress test.

Results: Participants with full-time sick leave during the study period (group 1) showed improved stress levels but no change in anxiety and depression levels. Anxiety, depression, and stress changed more favorably in participants with part-time or no sick leave than in those with full-time sick leave.

Conclusion: The results of this study indicate that investigation and appropriate treatment of psychological symptoms, including anxiety and depression, are important in multidisciplinary rehabilitation of patients with musculoskeletal disorders.

Keywords: anxiety, depression, musculoskeletal, rehabilitation, sick leave, stress

\section{Introduction}

Depression, pain, and somatic symptoms are common and often occur concomitantly, leading to symptoms that cannot be explained fully by a general medical condition and use of health care. ${ }^{1}$ It appears that with an increasing degree of pain, the risk of depression increases. On the other hand, symptoms such as pain are commonly associated with depression. ${ }^{2}$ However, pain is more often considered to lead to depression than the reverse. ${ }^{3}$

Pain in the lumbar region and the neck may not only reduce functional capacity but may also give rise to worry, anxiety, and depression. ${ }^{4}$ Impaired mental function may cause difficulties in concentration, fatigue, and pain in muscles and joints, which may lead to a deterioration of movement patterns as well as a restricted capacity for activity. ${ }^{4,5}$ Cognitive and behavioral factors play a significant role in the transition from acute to chronic pain in the back and neck. Among the most powerful cognitive and behavioral risk factors are pain-related fear, distress, and avoidance of activity. ${ }^{6}$ Prolonged pain tends to develop into a combination of physical, psychological, and social disabilities. ${ }^{7,8}$
Correspondence: Rita Sjöström Strömsund Health Centre,

SE-833 34 Strömsund, Sweden

Tel +46 670l 6545

Fax +46670I 6505

Email rita.sjostrom@jll.se 
In recent studies of a group of women and men with musculoskeletal disorders involving mainly neck and back pain, our research group found that most participants improved during a multidisciplinary rehabilitation program. This improvement was reflected in reduced disability and pain rating, and persisted during a follow-up period of 2 years. ${ }^{9}$ However, it was noted that a small number of participants with higher disability and pain rating at the beginning of the rehabilitation program were sick-listed during the program or for a longer period of up to 2 years after its completion. ${ }^{9}$

Lundgren and Molander ${ }^{10}$ see rehabilitation as a process of constant goal setting, new strategic choices, new measures, and evaluation. They state that the term "multidisciplinary" relates to the areas of knowledge on which the rehabilitation is based, and thus emphasize the aspect of theory. Rehabilitation is a multidisciplinary type of care, because it is based on knowledge generated in many different fields of science. The goal of multidisciplinary rehabilitation programs is that participants are able to learn to find management strategies for their problems and improve their quality of life, and possibly lower their consumption of outpatient treatment and other health care resources. Because there are few studies in this field, there is an urgent need for long-term scientific follow-up regarding the effects of multidisciplinary rehabilitation programs.

The aim of the present study, which was conducted on the same women and men as those who participated in the abovementioned study, ${ }^{9}$ was to analyze temporal changes in anxiety, depression, and stress in sick-listed and nonsick-listed persons with musculoskeletal pain during and up to 2 years after a 7-week multidisciplinary rehabilitation program. A further aim was to compare results between full-time sick-listed and part-time or nonsick-listed participants.

\section{Materials and methods}

\section{Participants}

Sixty-two persons with nonmalignant pain who had been consecutively referred to undergo a 7-week active rehabilitation program in a primary care setting were invited to participate in the study. Sixty persons (40 women, 20 men) who met the inclusion criteria agreed to take part.

The inclusion criteria were: working age, ability to understand and speak Swedish, having neck or back pain, having pain in the locomotor system when performing work tasks, having been accepted for the program by the regional social insurance office and their employer, and having been referred to the program by a doctor. Exclusion criteria were presentation with a serious pathological condition other than a locomotor system disorder and/or not having undergone a complete medical investigation.

The research ethics committee of Mid Sweden University reviewed the study and raised no objections from an ethics point of view. All participants gave their signed informed consent before the start of the study.

At the end of the 2-year study period, a group of 10 fulltime sick-listed participants (group 1), for whom data had been gathered earlier and used in a previous study, ${ }^{9}$ was compared with 49 participants who were part-time or not at all sick-listed (group 2, Table 1). The median age of group 1 was 48.5 years and of group 2 was 48.0 years.

\section{Procedure}

The multidisciplinary rehabilitation team treating the participants consisted of two registered physiotherapists, two registered nurses, one registered psychologist, one physician, one fitness instructor, and two secretaries.

The participants were recruited by physicians, physiotherapists, and nurses, or from the regional social insurance office or employers. Referral of patients to the regional social insurance office came via general practitioners. A decision about participation was made together with the

Table I Distribution according to gender (n), age (median and percentiles 25-75), civil status, profession, and diagnosis (n) in participants with full-time sickness benefit (group I) and with part-time or no sickness benefit (group 2) at the end of the followup period

\begin{tabular}{lll}
\hline & $\begin{array}{l}\text { Group I } \\
(\mathbf{n}=\mathbf{~ 1 0 )}\end{array}$ & $\begin{array}{l}\text { Group 2 } \\
(\mathbf{n}=\mathbf{5 0})\end{array}$ \\
\hline Gender & 7 & 33 \\
Women & 3 & 17 \\
Men & $48.5(40.5-51)$ & $48(42-53)$ \\
Age & & \\
Civil status & 6 & 26 \\
Married & 1 & 16 \\
Cohabiting partner & 0 & 2 \\
Noncohabiting partner & 3 & 6 \\
Single & 7 & 33 \\
$\begin{array}{l}\text { Profession } \\
\text { Blue-collar workers* }\end{array}$ & 3 & 17 \\
$\begin{array}{l}\text { White-collar workers** } \\
\text { Diagnoses }\end{array}$ & & 22 \\
Neck/chest pain & 5 & 16 \\
Low-back pain & 3 & 12 \\
$\begin{array}{l}\text { Other (general pain, hip pain, } \\
\text { shoulder pain) }\end{array}$ & 2 & \\
\hline Notes: 'Buecolr works, refs to & & \\
\hline
\end{tabular}

Notes: *Blue-collar workers, refers to workers with no supervisory position in industry, forestry, commerce, home health care, and medical care; **white-collar workers refers to employee or equivalent, eg, manager, supervisor or secretary; nurses, teachers, and nursery school teachers, who in the capacity of their profession, tutor other employees, students, patients, and spouses. 
participant, the regional social insurance office, and possibly the employer. Relevant investigations and treatments had to be completed prior to referral to the program. Information concerning the rehabilitation program was given as part of the physician's investigation, but information was also sent via post to the participants before the start of the program. The size of the rehabilitation group was a maximum of eight participants per group.

\section{Rehabilitation program}

The rehabilitation program was conducted over a period of 7 weeks, on 5 days a week, for 4 hours a day. The participants participated in the rehabilitation program for half days, allowing them to live in their regular home environment. The participants were taught training theory, ergonomics, and strategies for coping with pain and handling of stress. Lifestyle (sleep habits, diet, alcohol, tobacco), working life, and behavioral changes were also discussed. The participants practiced walking with or without a stick, participated in water gymnastics, back gymnastics, and in individual training programs, based on physical tests. ${ }^{11}$

Individual exercise programs were focused on flexibility of the spine and strengthening of the stabilizing muscle groups. Warm-up exercises and stretching were performed prior to the program. The participants also practiced different relaxation techniques and Qi-gong, as well as body awareness training. They were offered individual counseling by a psychologist throughout the rehabilitation period and, if considered necessary, psychological follow-up after the course., ${ }^{9,11,12}$

Group sessions were led by different team members, physiotherapists, nurses, a psychologist, and a fitness instructor. The different team members worked together. The participants also had regular once-weekly meetings with the team members during the 7-week rehabilitation program. The participants developed an individual rehabilitation plan at the start of the program. Follow-up was done at the end of the program and on different occasions over a 2 -year period. ${ }^{11}$

\section{Measurement instruments}

The study had a nonrandomized, prospective, interventional design. Data were obtained before and after the rehabilitation program and at intervals of 6,12 , and 24 months after completion of the program. All participants were evaluated using the Hospital Anxiety and Depression (HAD) scale ${ }^{13,14}$ and a self-rated stress test. ${ }^{15}$ The participants were not given any information about their scores from previous tests either before or during administration of the questionnaire.

\section{Sick leave data}

The level of sick leave was recorded by the participant before and at the end of the rehabilitation program and at intervals of 6,12 , and 24 months after its completion. The Swedish Social Insurance Agency is responsible for a large part of the social security system. This task includes investigating, deciding upon, and paying grants and allowances in the social insurance scheme. ${ }^{16}$

The most important part of sickness insurance is sickness benefits and the various forms of rehabilitation allowances. A sickness benefit is payable when there is sickness that reduces the work capacity of the insured by at least one quarter. A sickness benefit can be paid at 100\%, 75\%, 50\%, or $25 \%$, depending on the extent of reduction of the work capacity. The alternative sick-leave levels are decided by the Swedish sickness compensation system. ${ }^{16}$

\section{Hospital Anxiety and Depression scale}

The HAD scale consists of 14 items and has two subscales, one for measuring anxiety and the other for measuring depression. ${ }^{13}$ The scoring system ranges from absence of a symptom or the presence of positive features (scoring 0 ) to maximal presentation of symptoms or the absence of positive features (scoring 3 ). Thus, the higher the score, the greater the anxiety and/or depression. ${ }^{13,14}$ The HAD scale is considered to be a reliable instrument to screen for clinically significant anxiety and depression in patients attending a general medical clinic. The scale has also been shown to be a valid measure of the severity of these mood disorders. The internal consistency of the two subscales was examined by calculating correlations between each item and the total score of the remaining items in the subscales. Correlations for the anxiety items ranged from +0.76 to +0.41 and their level of statistical significance was $P<0.01$. The correlations ranged from +0.60 to +0.30 for the depression items and their statistical significance was $P<0.02 .^{13}$

\section{Stress test}

The Everyday Life Stress scale is an instrument for assessing the level of self-rated stress behavior. ${ }^{15}$ It consists of 20 statements referring to stress behavior in everyday life situations and is based on two major themes, ie, time urgency/impatience and easily aroused irritation/ hostility. The score ranges between 0 and 60 points, higher scores indicating more stressful reactions. Internal consistency between the 20 items is high (Cronbach's alpha 0.90). A five-point difference is of major clinical significance. ${ }^{15}$ 


\section{Statistical analysis}

The Statistical Package for Social Science version 12.0.1 (SPSS Inc, Chicago, IL) was used for the statistical analysis. The median, percentiles, and percentage rates were calculated for each measurement. Friedman's one-way analysis of variance, the Mann-Whitney U-test, and the Wilcoxon test were used to test for temporal change and the interaction between full-time sick-listed, part-time, or not at all sicklisted participants. Nonparametric techniques were used for ordinal data and small samples. ${ }^{17}$ The statistical significance level was set at $5 \%$.

\section{Results}

There were no differences in background characteristics (gender, civil status, profession, diagnosis) between the groups (see Table 1). All participants completed the rehabilitation program, with the exception of one woman who did not participate for personal reasons in measurements at the 2-year follow-up, but attended and filled in the questionnaires before and after the rehabilitation program and attended follow-up visits at 6 and 12 months. This woman was included in the study.

\section{Sick leave}

Before the rehabilitation program, 30 participants had full-time sick leave and 30 had part-time sick leave or no sick leave at all. At the start of the study, three participants were on a $75 \%$ sickness benefit, eight on $50 \%$, two on $25 \%$, and 17 had no sick leave. At 2-year follow-up, 10 participants were on full-time sick leave (group 1), while 49 had part-time sick leave or no sick leave (group 2). Three participants were on $75 \%$ sickness benefit, 11 were on $50 \%$, eight were on $25 \%$, and 27 had no sick leave. In group 1, nine were sick-listed full-time during the entire 2-year follow-up period while one participant became sicklisted full time after the measurement at 12 months.

\section{Hospital Anxiety and Depression scores}

Participants in group 1 had a lower anxiety score than those in group 2 at the beginning of the study, and experienced no change in anxiety between the start of the program and 2-year follow-up (see Table 2). Group 2 decreased their anxiety score $(P<0.0005)$ during the 2-year follow-up period (Figure 1). Group 1 participants had a higher depression score than those in group 2 before the start of the program (Table 2). Depression decreased in group $2(P<0.01)$ in contrast to the development in group 1 between the start of the rehabilitation program and the 2-year follow-up (Figure 2).

\section{Stress}

A decrease in stress was found in both groups at the 2-year follow-up compared with scores before the rehabilitation program (Table 2). In group 1, there was a decrease in stress after the rehabilitation program followed by an increased stress score at 6 months, followed by a decrease at the 12-month and 24-month follow-up visits. In group 2, stress gradually decreased and this reduction was maintained at the 2-year follow-up $(P<0.0005$, Figure 3$)$.

\section{Discussion}

In an earlier study of the outcome of multidisciplinary rehabilitation in patients with musculoskeletal pain, it was found that most participants improved in terms of selfreported physical disability and pain. ${ }^{9}$ This was particularly true in those who were not or only part-time sick-listed (ie, group 2 patients in the present study). However, in a subgroup of patients (group 1), amounting to $16 \%$ of our total study

Table 2 Anxiety, depression, and stress scores (medians and percentiles 25-75) in individuals with a full-time sickness benefit (group I) and with part-time or no sickness benefit (group 2) before rehabilitation and at 2-year follow-up

\begin{tabular}{llll}
\hline $\begin{array}{l}\text { Measurement } \\
\text { instruments }\end{array}$ & Group & $\begin{array}{l}\text { Score before rehabilitation } \\
\text { medians (percentiles) } \\
\text { group I }(\mathbf{n}=1 \mathbf{0}) \\
\text { group 2 }(\mathbf{n}=\mathbf{5 0})\end{array}$ & $\begin{array}{l}\text { Score at 2-year follow-up } \\
\text { medians (percentiles) } \\
\text { group I } \mathbf{n}=10\end{array}$ \\
group 2 $\mathbf{n}=\mathbf{4 9}$
\end{tabular}

Notes: $* * P<0.0005 ; * P<0.01$.

Abbreviations: HAD, Hospital Anxiety and Depression; NS, not statistically significant. 


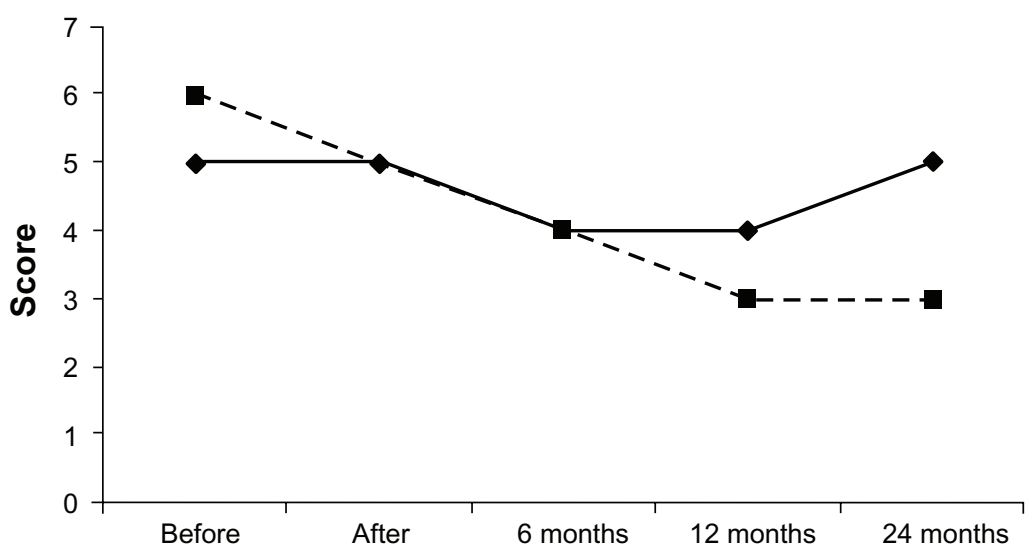

Figure I Development of the anxiety (HAD) score (y axis) in participants with a full-time sickness benefit (group I, thick line, filled squares) and with part-time or no sickness benefit (group 2, hatched line, filled squares, $P<0.0005$, Friedman's one-way analysis of variance) before and after the rehabilitation program and 6,12 , and 24 months after completion ( $\mathrm{x}$ axis)

Abbreviation: HAD, Hospital Anxiety and Depression.

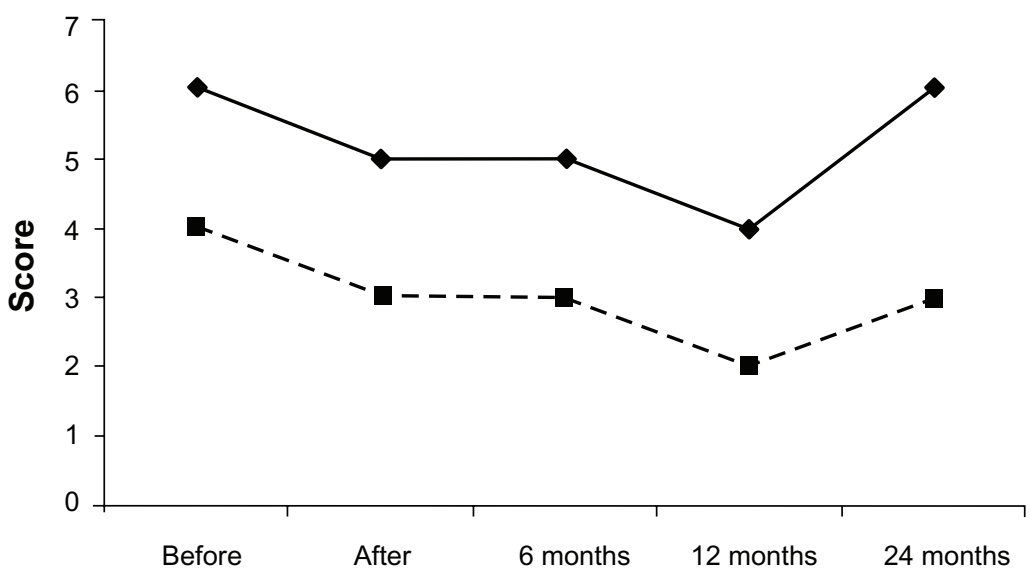

Figure 2 Development of the depression (HAD) score (y axis) in participants with a full-time sickness benefit (group I, thick line, filled squares) and with a part-time or no sickness benefit (group 2, hatched line, filled squares, $P<0.0$ I, Friedman's one-way analysis of variance) before and after the rehabilitation program and 6,12 , and 24 months after completion ( $\mathrm{x}$ axis).

Abbreviation: HAD, Hospital Anxiety and Depression.

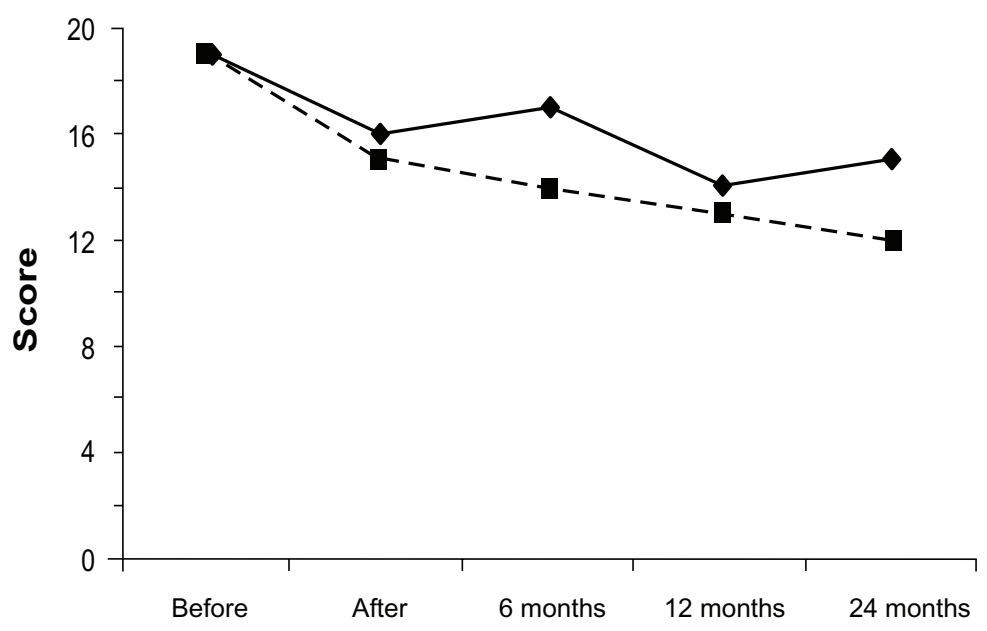

Figure 3 Development of the stress test score (y axis) in participants with full-time sickness benefit (group I, thick line, filled squares) and with part-time or no sickness benefit (group 2 , hatched line, filled squares, $P<0.0005$, Friedman's one-way analysis of variance) before and after rehabilitation program and at months 6,12 , and 24 after completion ( $\mathrm{x}$ axis) 
group, with full-time sick-listing during rehabilitation and who were still sick-listed at the 2-year follow-up, little or no improvement was recorded during and after rehabilitation. These participants had higher scores for disability and pain at the 2-year follow-up visit than before the start of the program. ${ }^{9}$

It was also found that anxiety and stress scores changed more favorably in group 2 than in group 1 during and after rehabilitation, and that the depression rating was higher in group 1 than in group 2 during the entire 2-year study period.

Group 1 reported lower self-estimated anxiety at the start of the rehabilitation program than group 2, but did not improve during the follow-up period, in contrast with group 2. The decrease in anxiety in group 2 was gradual and was maintained up to the 2-year follow-up. Group 1 showed higher self-estimated depression than group 2 throughout the study period. The development of the depression score was almost the same in the two groups, up until the 12-month follow-up, after which time there was an increase in group 1 but not in group 2 . The participants in our study had nonmalignant pain in the neck, chest, and lower back, and they had a mixture of short-term and long-term sick-listing.

People with chronic pain may suffer from pain-related anxiety. Belief that pain is a sign of damage or harm to the body, and that activities that might cause pain should be avoided, is also thought to be an important contributor to disability and adjustment among such patients. ${ }^{18,19}$ Therefore, it is important that the rehabilitation program is focused on teaching the participants strategies for handling the disorder in question, to give them a better understanding not only of symptoms such as pain and disability but also of anxiety and depression.

The instrument used for assessing the level of self-rated stress behavior ${ }^{15}$ in this study showed that participants in both groups decreased their levels of stress during the study period. The two groups had nearly the same stress score at the start of the rehabilitation program, but at the 2-year follow-up, group 2 had a lower score for stress than group 1. In another study it was shown that in stressed employees, the illness burden represented by absenteeism was not affected by a stress reduction program, and that there was no substantial difference in effectiveness between the cognitive and physical interventions. ${ }^{20}$ The participants in our rehabilitation program were offered a combination of theoretical and practical education and also individual guidance. They were offered individual counseling by a psychologist during their rehabilitation and if necessary during the follow-up period. At 5-year follow-up, after a multimodal program, Westman et al found a decrease in sick leave, improved quality of life, and reduction in pain. Improvements in perceived health and psychosomatic symptoms were also maintained at 5-year follow-up. ${ }^{21}$ Several other studies and reviews of multidisciplinary treatment with a functional restoration approach similar to ours have shown strong support for the efficacy of the treatments regarding return to work, psychosocial variables, quality of life, and pain reduction. $^{22}$

The present study has limitations that need to be considered. The total study group, and group 1 in particular, were small. The study group was also heterogeneous, in that participants had both specific and nonspecific disorders related to the neck, chest, and lower back. There was also a mixture of nonsick-listed participants, included for preventive purposes, and participants on short-term and long-term sick leave. This is a disadvantage, considering that the aim of the study was to analyze results in specific diagnostic groups.

The strength of the study was that all individuals in a geographical area who met the inclusion criteria were offered rehabilitation in our program. Virtually no alternative service providers were available. Thus, the results achieved in this study group are highly applicable to patients in primary health care, and the risk of selection bias is consequently small. Five measurements were taken over a 2-year period. There was good consistency between the results obtained with different test instruments over time. All instruments have been widely used and have shown good validity. ${ }^{13-15}$ The participants underwent measurements by the same physiotherapists on all occasions and the researcher did not know the subjects personally.

We showed in our study that participants with musculoskeletal disorders who were sick-listed full-time throughout the 2-year study period (group 1) did not deteriorate in anxiety, depression, or stress scores during that period. In a previous study, the same group of subjects was found to have high pain rating and high self-reported physical disability, with little or no improvement during and after rehabilitation. They even reported higher scores for pain rating and disability at the 2-year follow-up than before the start of the program. ${ }^{9}$ Participants who had parttime or no sick leave (group 2) showed an improvement in anxiety, depression, and stress during the 2-year study period. It has previously been reported that individuals with extreme pain prior to rehabilitation are at risk for having a lower rate of completion of rehabilitation, a higher rate of post-rehabilitation depression and disability, and lower 
levels of tolerance for physical activity. ${ }^{23}$ The participants who were sick-listed full-time in the present study did not benefit from the rehabilitation program. Their sick-listing did not change during the 2-year study period, and neither did their pain rating score or anxiety and depression score. These results indicate that persons with musculoskeletal pain and psychological symptoms may require rehabilitation with a different content from that which we were able to give this group. Our findings also indicate that investigation and appropriate treatment of psychological symptoms, including anxiety and depression, are important in multidisciplinary rehabilitation of musculoskeletal disorders.

\section{Conclusion}

Anxiety, depression, and stress changed more favorably in participants with part-time or no sick leave than in those with full-time sick leave during and after rehabilitation. The results indicate that investigation and appropriate treatment of psychological symptoms like anxiety, depression, and stress is essential in multidisciplinary rehabilitation of musculoskeletal disorders.

\section{Acknowledgments}

This study was supported by the Jämtland County Council, Sweden. The authors would like to thank Hälsan Rehabilitation, Strömsund, Sweden, and especially Ann Färdvall, Britt-Marie Bryntesson, and Marita Oscarsson, for their help in making this study possible.

\section{Disclosure}

The authors report no conflicts of interest in this work.

\section{References}

1. Henningsen P, Löwe B. Depression, pain, and somatoform disorders. Curr Opin Psychiatry. 2006;19(1):19-24.

2. Delgado PL. Common pathways of depression and pain. J Clin Psychiatry. 2004;65 Suppl 12:16-19.

3. Fishbain DA, Cutler R, Rosomoff HL, Rosomoff RS. Chronic painassociated depression: antecedent or consequence of chronic pain? A review. Clin J Pain. 1997;13(2):116-137.

4. SBU. The Swedish Council on Technology Assessment in Health Care. Back pain, neck pain volume I 2000. http://www.sbu.se 2012.

5. SBU. The Swedish Council on Technology Assessment in Health Care. Sick-listing- reasons, consequences and praxis. A review 2003. http://www.sbu.se 2012 .

Journal of Multidisciplinary Healthcare

\section{Publish your work in this journal}

The Journal of Multidisciplinary Healthcare is an international, peerreviewed open-access journal that aims to represent and publish research in healthcare areas delivered by practitioners of different disciplines. This includes studies and reviews conducted by multidisciplinary teams as well as research which evaluates the results or conduct of such teams or
6. Boeresma K, Linton SJ. Screening to identify patients at risk: profiles of psychological risk factors for early intervention. Clin J Pain. 2005;21(1): $38-43$.

7. Soares JJ, Jablonska B. Psychosocial experiences among primary care patients with and without musculoskeletal pain. Eur J Pain. 2004;8(1): 79-89.

8. Karjalainen K, Malmivaara A, van Tulder M, et al. Multidisciplinary biopsychosocial rehabilitation for sub-acute low-back pain among working age adults. Cochrane Database Syst Rev. 2003;2:CD002193.

9. Sjöström R, Alricsson M, Asplund R, Nordenmark M. Back to worka two year outcome of a multidisciplinary rehabilitation programme focused on physical function and pain. Disabil Rehabil. 2009;31(3): $237-242$.

10. Lundgren C, Molander C. Teamwork in Medical Rehabilitation. Stockholm, Sweden: Liber AB; 2008. Swedish.

11. Sjöström R, Alricsson M, Asplund R. Back to work - evaluation of a multidisciplinary rehabilitation programme with emphasis on musculoskeletal disorders. A two-year follow-up. Disabil Rehabil. 2008;30(9):649-655.

12. Sjöström R, Asplund R, Alricsson M. Two-year outcome of a multidisciplinary vocational rehabilitation programme focused on range of motion of the neck and back. Work. 2010;37(4):341-348.

13. Zigmond AS, Snaith RP. The Hospital Anxiety and Depression Scale. Acta Psychiatr Scand. 1983;67(6):361-370.

14. Baldaccihno DR, Bowman GS, Buhagiar A. Reliability testing of the hospital anxiety and depression (HAD) scale in the English, Maltese and back-translation versions. Int J Nurs Stud. 2002;39(2):207-214.

15. Claesson M, Burell G, Birgander LS, Lindahl B, Asplund K. Psychosocial distress and impaired quality of life - targets neglected in the secondary prevention in women with ischaemic heart disease. Eur J Cardiovasc Prev Rehabil. 2003;10(4):258-266.

16. Swedish Social Insurance Agency. Your Guide to Försäkringskassan and social insurance in Sweden. Försäkringskassan; 2008.

17. Pallant J. SPSS, Survival Manual. A Step by Step Guide to Data Analysis Using SPSS for Windows, 3rd ed. Sydney Australia: The McGraw-Hill Companies; 2007.

18. Geisser ME, Robinson ME, Miller QL, Bade SM. Psychosocial factors and functional capacity evaluation among persons with chronic pain. J Occup Rehabil. 2003;13(4):259-276.

19. Vowles KE, Zvolensky MJ, Gross RT, Sperry JA. Pain-related anxiety in the prediction of chronic low-back pain distress. J Behav Med. 2004; 27(1):77-89

20. van Rhenen W, Blonk RWB, Schaufeli WB, van Dijk FJH. Can sickness absence be reduced by stress reduction programs: on the effectiveness of two approaches. Int Arch Occup Environ Health. 2007; 80(6):505-515.

21. Westman A, Linton SJ, Theorell T, Öhrvik J, Wahlén P, Leppert J. Quality of life and maintenance of improvements after early multimodal rehabilitation: a 5-year follow-up. Disabil Rehabil. 2006; 28(6):437-446.

22. Schonstein E, Kenny DT, Keating J, Koes BW. Work conditioning, work hardening and functional restoration of workers with back and neck pain. Cochrane Database Syst Rev. 2003;1:CD001822.

23. McGeary DD, Mayer TG, Gatchel RJ. High pain ratings predict treatment failure in chronic occupational musculoskeletal disorder. J Bone Joint Surg Am. 2006;88(2):317-325.

healthcare processes in general. The journal covers a wide range of areas and welcomes submission from practitioners at all levels, from all over the world. The manuscript management system is completely online and includes a very quick and fair peer-review system. Visit http://www.dovepress.com/testimonials.php to read real quotes from published authors. 